\title{
BMJ Open Quality Promoting low-flow anaesthesia and volatile anaesthetic agent choice
}

\author{
Louise A Carter, ${ }^{1}$ Molola Oyewole, ${ }^{2}$ Eleanor Bates, ${ }^{3}$ Kate Sherratt ${ }^{4}$
}

To cite: Carter LA, Oyewole M, Bates $\mathrm{E}$, et al. Promoting low-flow anaesthesia and volatile anaesthetic agent choice. BMJ Open Quality 2019;0:e000479. doi:10.1136/ bmjoq-2018-000479

Received 30 August 2018 Revised 2 August 2019 Accepted 20 August 2019
Check for updates

(C) Author(s) (or their employer(s)) 2019. Re-use permitted under CC BY-NC. No commercial re-use. See rights and permissions. Published by BMJ.

${ }^{1}$ Anaesthetic Department, Royal Brompton and Harefield NHS Foundation Trust, London, UK ${ }^{2}$ Anaesthetic Department, Royal National Throat Nose and Ear Hospital, London, UK

${ }^{3}$ Anaesthetic Department, Brighton and Sussex University Hospitals NHS Trust, Brighton, UK

${ }^{4}$ Anaesthetic Department, Royal Free London NHS Foundation Trust, London, UK

Correspondence to Dr Kate Sherratt; katesherratt@nhs.net

\section{ABSTRACT}

Background As doctors, we are increasingly aware of the financial implications of our practice. The need to work in a more conscientious, efficacious and cost-effective manner is greater than ever before. Environmental and financial benefits can be seen through employing the use of lowflow anaesthesia.

Aims This quality improvement project aimed to make anaesthetic practice more environmentally friendly and to reduce departmental spending. This could be achieved by promoting the use of low-flow anaesthesia and by encouraging isoflurane use where appropriate.

Methods All anaesthetic consultants and trainees were invited to fill out an initial questionnaire relating to their personal preferences and practices when conducting anaesthesia. There were specific questions relating to lowflow anaesthesia and isoflurane use. Our main measure of improvement was any decrease in the number of bottles of volatile agent ordered by the department from pharmacy. Monthly spot audits were conducted to assess gas flow rates and volatile agent use in theatre. Departmental spending figures relating to the purchase of volatile agent bottles were obtained from pharmacy. Information was then disseminated to anaesthetists on a monthly basis via a 'low-flow board', which showed pictorial and graphical representations of differing gas flows and volatile agent usage in relation to cost.

Results Our project showed a trend for the increased use of low-flow anaesthesia within the department. We also showed a decrease in the number of bottles of volatile agent ordered: $18 \%$ fewer bottles ordered compared with the same period the previous year. This represented a $25 \%$ decrease in total departmental expenditure on volatile agents despite an increase in theatre activity.

Conclusion Increasing awareness regarding anaesthetic choices and promoting low-flow anaesthesia and isoflurane use, translated into an overall decreased departmental spend on volatile agents without affecting patient care.

\section{PROBLEM}

As doctors, we are increasingly made aware of the financial implications of our practice and are constantly being asked to look at ways of working in a more efficacious and cost-effective manner. In the Royal Free Hospital (RFH) anaesthetic department, we have been looking at ways of contributing to quality improvement $(\mathrm{QI})$ within the department and to the organisation as a whole.
The RFH is a large teaching hospital in North London with over 800 beds and around 10000 members of staff. It serves a very diverse population in terms of ethnicity and has a significantly higher elderly population than other parts of London. The anaesthetic workload is extremely varied and includes adult and paediatric practice over 16 main theatres, 3-day case theatres and two non-theatre areas. Operations performed include liver transplants and hepatobiliary surgery, renal transplants and renal surgery, orthopaedics, and general and plastic surgery. Theatre activity ranges between 1100 and 1600 cases per month.

The idea for this QI project looking at low-flow anaesthesia is not new and has been investigated previously in attempts to become more environmentally friendly and to reduce departmental costs. These projects have been short lived, however, and improvements have not been maintained (mainly due to turnover of staff). The department gets regular updates from pharmacy highlighting anaesthetic drug spend, and two of the highest drug costs are for the volatile anaesthetic agents: desflurane and sevoflurane. We wanted to decrease the departmental spend on volatile agents per month.

To tackle this, we aimed to improve on two specific areas of anaesthetic practice from September 2016 to March 2017. Our aims were to promote the use of low-flow anaesthesia and to encourage the use of isoflurane where appropriate (isoflurane bottles are significantly cheaper to purchase than sevoflurane and desflurane). We aimed to achieve that a total of $90 \%$ of all anaesthetics would be conducted using fresh gas flow rates of $<1 \mathrm{~L} / \mathrm{min}$ within $10 \mathrm{~min}$ of entering theatre and for a $20 \%$ reduction in the number of bottles of volatile agents ordered per month. This would then be translated into a cost saving for the anaesthetic department. 


\section{Background}

We wanted to reduce costs and to provide environmental benefits during our project by promoting the use of low-flow anaesthesia, but what exactly does this mean? Low-flow and minimal-flow anaesthesia are characterised by the rate of fresh gas flow $(\mathrm{L} / \mathrm{min})$, which is fed into the breathing gas system of the circuit (eg, the anaesthetic machine). The concept of low-flow anaesthesia is not new, having been first described in 1952 by Foldes et al. ${ }^{12}$ They described a technique for nitrous oxide-oxygen anaesthesia with a gas flow of $1 \mathrm{~L} / \mathrm{min}$. Following on from this, Virtue described a technique for minimal flow anaesthesia in $1974 .^{3}$ In this technique, the flows are reduced to $0.5 \mathrm{~L} / \mathrm{min}$. Although there is no absolute and universally accepted definition of low-flow anaesthesia, it certainly implies a carrier gas flow less than that attainable with a non-absorber breathing system,.$^{4}$ Among the anaesthetic community worldwide, flow rates of $\leq 1 \mathrm{~L} / \mathrm{min}$ would be compatible with an accepted definition of low-flow anaesthesia.

There are multiple benefits of employing low-flow anaesthesia. There are obvious environmental and economic benefits since lowering gas flow rates through the breathing circuit reduces the amount of volatile agent, which leaks out of the circuit via the adjustable pressure limiting valve and the scavenging system. Very little of the volatile agent is metabolised by the patient, so there is greater conservation of volatile agent per case and less released into the atmosphere as environmental pollution. As anaesthetists, we are more aware than ever of the environmental impact of our practice. The halogenated volatile anaesthetic agents are classed as greenhouse gases; thus, they contribute to global warming and are potentially damaging to the ozone layer. ${ }^{5}$ Anaesthetic gases currently represent $5 \%$ of the carbon footprint for all acute NHS organisations, ${ }^{6}$ and it has been estimated that the annual warming effect of all volatile agents is the equivalent of one coal fired power station. ${ }^{7}$ Anaesthetists, therefore, have a major role to play in contributing to a greener operating theatre.

Another benefit of using low-flow anaesthesia is climatisation. Where anaesthetic practice does not routinely involve a heat and moisture exchanger, humidity and moisture within the breathing circuit may be maintained by the use of low flows. Finally, there are physiological benefits to using low-flow anaesthesia as it improves the dynamics of the inhaled gases ${ }^{8}$ and increases mucociliary clearance. It also helps to maintain body temperature and reduce fluid losses. ${ }^{9}$

Adopting the use of a low-flow anaesthetic technique in our regular anaesthetic practice should also aid greater understanding of breathing systems and the pharmacokinetics of inhalational anaesthesia. ${ }^{4}$

Previous audits and surveys looking at this within the RFH have shown intermittent improvements, but usually, these have not been maintained due to trainee rotation and therefore discontinuation of the projects.
There was also an element of fatigue among the anaesthetic staff.

We aimed to communicate effectively with colleagues to achieve a sustained improvement in the use of low-flow anaesthesia alongside the promotion of isoflurane use by maintaining an ongoing high profile with this project within the anaesthetic department.

\section{Baseline measurement}

Our initial approach to achieving our project aims was to give this project a high profile within the anaesthetic department as something that is relevant to all anaesthetists. A polite but clearly worded email was sent out to all consultants and trainees in September 2016 explaining the rationale behind our low-flow anaesthesia QI project and outlining how we would be conducting our data collection. We proposed handing out an initial questionnaire in September 2016 enquiring about individual anaesthetic practice and following this up with a spot audit in theatre, looking at volatile agent use and gas flow rates. These initiatives would be conducted by an anaesthetic consultant and two anaesthetic trainees coordinating the project.

We began by inviting all anaesthetic consultants and trainees to fill out a questionnaire relating to how they prefer to conduct anaesthesia during their theatre cases. We specifically asked about their preferred anaesthetic agent and gas flow rates that they would associate with low-flow anaesthesia. We focused one question on isoflurane use and whether or not the Royal Free anaesthetists were happy to use it and under which circumstances. We also asked for any comments/feedback about our proposed project.

Twenty-two anaesthetists gave responses to the questionnaire of which 19 were consultants. Most agreed that low-flow anaesthesia would be achieved at flow rates of 1 or $<1 \mathrm{~L} / \mathrm{min}$. Only four consultants stated that their volatile agent of choice would be isoflurane.

Spot audits were carried out in theatre monthly from September 2016 to March 2017. Data were collected from between 10 and 13 different theatres as there was not always a patient in theatre at the time of the audit or the patient was not having surgery performed under general anaesthesia. Data were collected on volatile agent use, isoflurane and sevoflurane availability, and fresh gas flow rates. The first spot audit in September 2016 yielded data from 13 theatres. Thirty-six percent of the cases were found to have flow rates of $<1 \mathrm{~L} /$ min, but in $63 \%$ of the cases, flow rates were $>1 \mathrm{~L} /$ min. Desflurane was the most popular volatile agent in use $(36 \%$ of cases), followed by isoflurane $(31 \%)$ and sevoflurane $(17 \%)$. The remaining anaesthetics were conducted using total intravenous anaesthesia. The availability of isoflurane vaporisers did not seem to be an issue contributing to these figures as they were universally available in all anaesthetic rooms and in all but two operating theatres. 
These results were presented to the anaesthetic department audit meeting in September 2016. Emphasis was placed on moving forward with this QI project by encouraging isoflurane use and the use of low flows.

In order to meet our aims of achieving $90 \%$ fresh gas flow rates of $<1 \mathrm{~L} / \mathrm{min}$ and a $20 \%$ decrease in the number of volatile bottles ordered, we planned to continue the spot audits monthly for 6 months using the same proforma. Results would be reported to the department and feedback from colleagues would be actively encouraged.

\section{Design}

The QI project team initially consisted of a Consultant naesthetist and anaesthetic trainee (ST5) but was expanded to include another anaesthetic trainee (ST3) and the lead operating department practitioner (ODP) for theatres. Throughout the project, regular email contact regarding theatre activity and volatile anaesthetic use/costings was maintained between the anaesthetic QI team and the senior pharmacist for intensive care and theatres.

Our monthly spot audits of gas flow rates in theatres and volatile use were conducted from September 2016 to March 2017. These were conducted by the anaesthetic trainees. We planned to thank the department for their participation in the project and feedback on the latest spot audit findings at our weekly Friday morning anaesthetic departmental meetings. We also planned to give actual costing figures based on our information from pharmacy about monthly spending on volatile anaesthetics so that colleagues could see the savings for themselves.

Most anaesthetists were amenable to the data collection process, but we were aware that some might find it intrusive to their practice when we started the project. We introduced another intervention to help smooth over any remaining negativity which took the form of a large, 'low-flow board', placed on the wall in the anaesthetic department. This highlighted our project aims alongside pictorial and graphical representations of monthly progression. This is now a permanent feature in the anaesthetic department and colleagues responded well to it. We felt that this would help in the sustainability of the project. We also sent out regular email updates to the anaesthetic body highlighting the improvements we had made as a group, to encourage continued engagement with the project.

The QI team was in regular contact via email throughout the project and met in person whenever possible to discuss further interventions as the project progressed. Through this discussion, we were able to involve and gain support from the lead theatre ODP and our departmental lead clinician as we came up with new interventions. These included making isoflurane vaporisers available in all anaesthetic rooms and inside theatres and removing sevoflurane vaporisers from inside all theatres.
Anaethetic Gas Usage (bottles) vs Activity Mar 2015 - Mar 2017

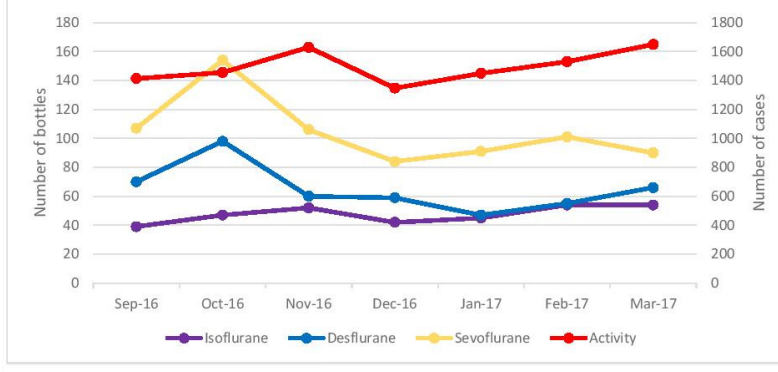

Figure 1 Graph showing the number of bottles of each volatile agent ordered per month. Note that there is a 1-month lag between the changes we implemented and an effect on bottles ordered. Our project started in September 2016; thus, results are relevant from October 2016.

\section{Strategy}

Our SMART aim was to achieve fresh gas flow rates of $<1 \mathrm{~L} / \mathrm{min}$ in $90 \%$ of cases within 6 months. We also aimed to decrease the number of volatile bottles ordered by $20 \%$ over the same period. These aims could be achieved via two methods: promoting low-flow anaesthesia and increasing the use of isoflurane (as opposed to sevoflurane or desflurane) where appropriate. We undertook a QI project over this period with multiple snapshot audits and phased interventions.

We took monthly snapshot audits of the gas used, flow used, availability of gases and most senior anaesthetist present. The number of bottles ordered was measured monthly by our pharmacy department (figure 1). We verified at the beginning of the project that the ordering of anaesthetic gases was determined by a senior ODP. $\mathrm{He} /$ she would review the stock levels at the beginning of the month, predict theatre activity and order accordingly. We noted that this meant any improvements implemented would only become evident the following month (creating a lag between our actions and measurement of their effect).

We also looked at levels of theatre activity to ensure any decrease in spend could not be attributed to a decrease in theatre activity.

Cycle 1 (September-October): Our initial plan was to increase awareness of the pharmacoeconomics of volatile agents. We collected data on our colleagues' awareness of low-flow anaesthesia and the anaesthetic practices within our department (including flow rates and volatile agent choice). We presented these data together with their environmental and economic impact at our weekly departmental meeting. This led to a $31 \%$ increase in the number of anaesthetists practicing low-flow anaesthesia. It also led to a $27 \%$ increase in the use of isoflurane in our subsequent spot audit.

Cycle 2 (October-November): We recognised that providing information as to how anaesthetic choices affected departmental finances had made a positive 


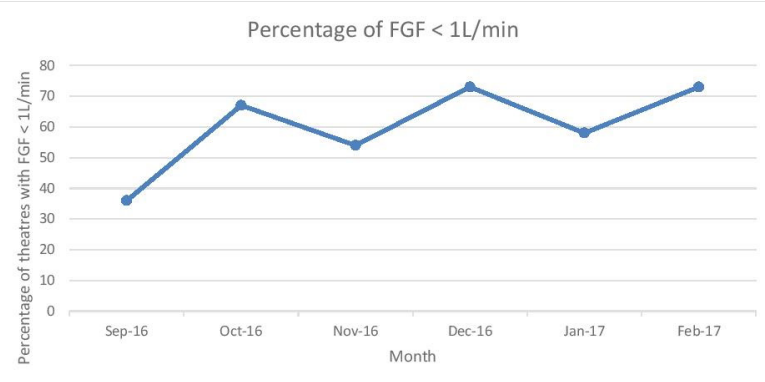

Figure 2 Graph showing the percentage of theatres with FGF $<1 \mathrm{~L} /$ min over the course of our project. FGF; fresh gas flow.

impact. However, we also knew that monthly spot audits and presentations would not be sustainable. We therefore looked for alternative methods of information delivery. We decided to test whether email would be a good method of distributing this information to our colleagues. Our email showed the results of our spot audit together with a financial statement of the savings achieved. We hypothesised that although spot audit figures would not necessarily continue, the financial statement would provide a clear reminder that choices within theatre had financial repercussions. This did not achieve any improvement. In fact, our low fresh gas flow (FGF) rates fell by $13 \%$ between October and November (figure 2). We noted that we had a new intake of anaesthetic trainees on November, and thus our mechanism of information delivery was still not robust. Disappointing, in this cycle there was also a decrease in the use of isoflurane. This correlated with a $31 \%$ decrease in its availability within theatre.

Cycle 3 (November-December): We hypothesised that a 'low-flow' board in the anaesthetic department would be a simple reminder to all of our colleagues about the economic and environmental impact of our practices in theatre. The information provided on this board included information on FGF rates achieved from our previous audits, the rates of use of individual agents and the savings/costs incurred by the department. The lack of isoflurane available (noted on our spot audit) was also discussed with our lead ODP. We aimed to achieve $100 \%$ availability within the anaesthetic rooms and theatres within 1 month. These changes enabled us to achieve a $19 \%$ increase in low-flow anaesthesia compared with the previous month. We also saw a $32 \%$ increase in the use of isoflurane in theatre and a $13 \%$ decrease in the use of sevoflurane. This correlated with isoflurane being available in $100 \%$ of theatres.

Cycle 4 (December-January): After discussion with our departmental head, we decided to remove sevoflurane from anaesthetic machines within theatre (we did not remove it from theatre itself). We noted that $58 \%$ of theatres were achieving the targets of low FGFs. Of the $34 \%$ not achieving our target FGF, 25\% had FGF rates of $1.2 \mathrm{~L} / \mathrm{min}$. We also noted that once sevoflurane was removed from the back bar, none of the cases used sevoflurane. Our use of isoflurane did not increase proportionally; instead, we saw an increase in desflurane use. Engagement with our pharmacists allowed us to show a $34 \%$ decrease in expenditure on inhaled agents compared with the same period the previous year, despite a $4 \%$ increase in theatre activity.

Cycle 5 (January-February): The details of our project were presented to new anaesthetic trainees at their induction. We also invited a representative from the department to advise as to the optimal use of desflurane (namely, the 'rule of 24', which allows users to achieve a quick wash-in of desflurane on induction without excessive waste). This rule states that the percentage concentration multiplied by FGF should equal 24 . Not only does this increase efficiency, bu also it decreases sympathetic stimulation to the patient. This information was added to our low-flow board. We noted that use of desflurane remained high $(60 \%)$. This may be explained by the fact that in this snapshot, $100 \%$ of patients receiving inhaled agents were intubated. Although isoflurane is perfectly acceptable, the quick onset/offset is for many a reason to use desflurane. Low-flow rates remained high with just under $80 \%$ of cases having FGF $<1 \mathrm{~L} / \mathrm{min}$ (figure 2). The majority of the FGF rates between 1 and $2 \mathrm{~L} / \mathrm{min}$ could be explained by a recent disconnection in the circuit.

\section{RESULTS}

Our main outcome was a percentage decrease in the number of volatile bottles ordered. We noted that after the first audit cycle, there were no FGF rates over 2L/ min recorded. The general trend was for an increase in low-flow anaesthesia. Increases in isoflurane use were more difficult to demonstrate as the data fluctuated. We were pleased to see that overall, we achieved an $18 \%$ reduction in bottles ordered compared with the same period last year. This represented a $25 \%$ decrease in our total expenditure on volatile agents. This was despite an increase in theatre activity. The heavy caseload in our teaching hospital meant that our small changes in flow and volatile agent had a large financial and environmental impact.

\section{Lessons and limitations}

The project aim was to decrease the waste and therefore cost of anaesthetic inhaled agents. The effects of this would be both environmentally friendly and economically sensible. Importantly, this could be achieved without compromising patient care. We wanted to implement a self-sustaining change that would require limited future input. To achieve this, we realised that we would require 'buy-in' from the anaesthetic department as a whole and, most importantly, from anaesthetic consultants who would continue the changes in their daily practice and teach rotating trainees. This would ultimately require a change in culture. 
The true cost of the inhaled agents used in one patient anaesthetic can be attributed to four key things: the FGF $(\mathrm{L} / \mathrm{min})$, the concentration $(\%)$ of gas delivered, the cost per millilitre and the duration of the anaesthetic, ${ }^{10}$ Only the first two are within our control. We found that 'low flow' was a relatively easy concept to promote and was easily accepted by our colleagues. Although newer anaesthetic machines have an inbuilt feature allowing clinicians to observe the cost per hour of their anaesthetic, the machines in our department do not. It was therefore necessary to demonstrate this in our weekly departmental meeting. We gave examples of how the cost of inhaled agents increased significantly at higher FGF rates without conferring any additional patient benefit. We therefore encouraged vigilance on flow rates during cases. Simply providing this information was enough to encourage a change in the flow rates within our department (cycle 3).

However, if our project had only targeted FGF rates, we would not have seen the improvements that we did. Promoting a change in inhaled agent, where appropriate, was slightly more difficult. A key lesson for us was that changing culture cannot be achieved sustainably via one mechanism. Our audit cycles allowed us to evaluate the financial impact of our changes in addition to the cultural feelings towards them. For example, when encouraging people to consider the isoflurane as a financial decision, we were met with some resistance. The reasons for this are plentiful. Anaesthesia is well known for being a specialty that embraces the idea that there is more than one way to skin a cat. Our training exposes us to a variety of different methods to anaesthetise similar patient groups. We are encouraged to observe and question individualised anaesthetic 'recipes' and ultimately form our own. The choice of anaesthetic technique employed by many is therefore a mixture of techniques previously observed, available literature and personal preference. It is only in the later stages of one's career that resource allocation may be considered. Our experience is that as a profession, there is some reluctance to factor in cost when making clinical decisions. For example, in healthy patients undergoing minor procedures, the choice to use isoflurane instead of the more expensive sevoflurane is largely a personal preference. Advising 'so-called' prescriptive choices can be viewed as an infringement on one's anaesthetic technique. To overcome this barrier to change, we used our low-flow information board to show continuous information on such choices and how they affected our departmental spend. We also emailed monthly updates (financial statements so to speak) providing the department with comparisons of costs this year compared with the previous year (taking into account levels of activity). In publicising our departmental finances to everyone (juniors and seniors alike), we felt that we increased the sense of responsibility our colleagues felt to the financial well-being of our department. In hindsight, announcing that we would be adding labels to anaesthetic machines and welcoming discussion prior to implementing may have improved their reception.

Maintaining standards of education regarding the pharmacoeconomics of inhaled agents was also key learning. We therefore included a segment into the trainees' induction programme, highlighting the benefits of low-flow anaesthesia and the financial impact. We invited desflurane representatives to educate trainees on the rule of 24, providing methods to quickly achieve the required minimum alveolar concentration (MAC) without excessive flow rates.

We also realised during the project that we would require some help from our operating departmental practitioner colleagues (ODPs). As mentioned, the selection of inhaled volatile agent can be attributed to many things, of which one is personal preference. We sought help from the ODP lead to remove sevoflurane from anaesthetic machines within theatre while keeping it available in the anaesthetic room. In doing so, we aimed to make it an active choice to use sevoflurane and thus hopefully to encourage a second thought as to whether this was the most appropriate choice. This led to a significant decrease in the use of sevoflurane. Earlier ODP engagement/the use of an ODP link for the project may have yielded earlier results (cycle 3 ).

Limitations of this project include the small sample size of our snapshot audits looking at flow. However, our aim in this project was to get an idea of the general trends in departmental activity. We used cost as our primary outcome as FGF rates will change throughout the course of the cases and depend on many factors, for example, recent circuit disconnection, degree of leak and airway used. Moreover, previous audits have found it difficult to demonstrate any additional significant benefit once FGFs are $<2 \mathrm{~L}$. We felt that a decrease in spend on inhaled agent was therefore a more sensitive marker. However, although we recorded the percentage of cases using inhaled agents (vs total intravenous anaesthesia or regional anaesthesia) in our snapshot audit, there was no way to determine if this was an accurate reflection for the month as a whole.

The cost of volatile agents, for example, desflurane, also changed compared with the previous year during our audit. We corrected for this when calculating our percentage departmental savings. We noted that during some of our snapshot audits, the presence of paediatric cases, which typically requires higher FGF rates, featured heavily. This must be taken into consideration and our data interpreted with care.

\section{CONCLUSION}

This project aimed to decrease spending on anaesthetic volatiles within our department without affecting patient care. We were able to identify a number of different methods through which this could be achieved. We felt that our main barrier was the perception of prescriptive anaesthesia/reduced choice. We used multiple 
methods to overcome this. Increasing the awareness of the financial impact of anaesthetic choices was a useful tool. Our low-flow board achieved this and will be continually updated by our low-flow lead in order to ensure the sustainability of the project.

Acknowledgements We thank Bryan 0'Farrell (senior pharmacist, Intensive Care and Theatres) for his help throughout this project. LAC, MO and EB no longer have affiliation with the Royal Free Hospital, London, at the time of submission of this quality improvement report and are now working at other hospitals.

Contributors LAC and MO contributed equally to this paper as joint first authors in terms of data collection and writing up both the first and revised drafts. Both conducted the monthly audits of anaesthetic volatile agent use and gas flow rates for the duration of the project. EB contributed to the initial idea behind this quality improvement project and devised a driver diagram that was passed on to KS and inspired her to take the project on in a robust manner. KS oversaw the quality improvement project as the supervising consultant and provided advice and liaison between the anaesthetic and pharmacy departments. KS also reviewed the initial and revised drafts of the manuscript and approved the final draft. Bryan O'Farrell (senior pharmacist, Intensive Care and Theatres, The Royal Free Hospital, London) provided tabular and graphical information regarding the pharmacoeconomics surrounding this quality improvement project.

Funding The authors have not declared a specific grant for this research from any funding agency in the public, commercial or not-for-profit sectors.

Competing interests None declared.

Patient consent for publication Not required.

Provenance and peer review Not commissioned; externally peer reviewed.
Open access This is an open access article distributed in accordance with the Creative Commons Attribution Non Commercial (CC BY-NC 4.0) license, which permits others to distribute, remix, adapt, build upon this work non-commercially, and license their derivative works on different terms, provided the original work is properly cited, appropriate credit is given, any changes made indicated, and the use is non-commercial. See: http://creativecommons.org/licenses/by-nc/4.0/.

\section{REFERENCES}

1. Foldes FF, Ceravolo AJ, Carpenter SL. The administration of nitrous oxide-oxygen anesthesia in closed systems. Ann Surg 1952;136:978-81.

2. Baum J. Low flow anaesthesia. 2nd edn. Butterworths, 2001.

3. Virtue RW. Minimal-flow nitrous oxide anesthesia. Anesthesiology 1974:40:196-8.

4. Nunn G. Low-Flow anaesthesia. Continuing Education in Anaesthesia Critical Care \& Pain 2008;8:1-4.

5. Yasny JS, White J. Environmental implications of anesthetic gases. Anesth Prog 2012;59:154-8.

6. Carbon Footprint from Anaesthetic gas use, 2013. Available: http:// www.sduhealth.org.uk/documents/publications/Anaesthetic_gases_ research_v1.pdf

7. Sulbaek Andersen MP, Nielsen OJ, Wallington TJ, et al. Medical intelligence article: assessing the impact on global climate from general anesthetic gases. Anesth Analg 2012;114:1081-5.

8. Kleemann PP. Humidity of anaesthetic gases with respect to low flow anaesthesia. Anaesth Intensive Care 1994;22:396-408.

9. Aldrete JA, Cubillos P, Sherrill D. Humidity and temperature changes during low flow and closed system anaesthesia. Acta Anaesthesiol Scand 1981;25:312-4.

10. Chernin EL. Pharmacoeconomics of inhaled anesthetic agents: considerations for the pharmacist. Am J Health Syst Pharm 2004;61 Suppl 4(suppl_4):S18-S22. 